\title{
Multi-Functionality Control, Power Filtering Single-Phase Grid-Connected Photovoltaic System
}

\author{
Arckarakit Chaithanakulwat \\ Department of Electrical Engineering, Dhonburi Rajabhat University, Samutprakan, Thailand \\ Email address: \\ chaithanakul@gmail.com \\ To cite this article: \\ Arckarakit Chaithanakulwat. Multi-Functionality Control, Power Filtering Single-Phase Grid-Connected Photovoltaic System. American \\ Journal of Electrical Power and Energy Systems. Vol. 8, No. 2, 2019, pp. 62-70. doi: 10.11648/j.epes.20190802.14
}

Received: February 26, 2019; Accepted: April 12, 2019; Published: May 17, 2019

\begin{abstract}
This research proposes the control power filtering single-phase grid-connected photovoltaic system using a single stage converter with active and reactive power filter functionality (ARPFF). The proposed system offers multi-functionality, namely the excessive power transfer from the nonlinear load on the grid, simultaneously acting as an active power filter to compensate for reactive power and to mitigate harmonics of the grid current resulting in nearly unity grid power factor, the capability of reactive power control and maximum power point tracking of the photovoltaic modules. The implemented system tested under various conditions such as power transfer with different current command throughout maximum power point transfer at different insolation, a step change in nonlinear load level, and reactive power control supplied to the grid. The experimental results are in accordance showing the correctness of the proposed technique.
\end{abstract}

Keywords: Active Filters, Reactive Filters, Current Control, Voltage Control, Power Quality

\section{Introduction}

The rapid development of industry, the overuse of fossil fuel results in environmental pollution, greenhouse effect and ecological damage. Adopting renewable and clean energy resources to replace fossil fuel is imperative. Renewable-Energy resources, solar energy is obtainable readily. However, the demand for photovoltaic (PV) panel has been increasing more, the output voltage and current of a photovoltaic vary with irradiation, panel temperature, and power loading nonlinearly [1]. The power loading non-linear currently produces harmonic currents and affect the power quality of the joints of other loads. Therefore, to reduce or eliminate the need to use the passive filter circuit consisting of inductor and capacitor, such as non-linear load on the single-phase system, the harmonic removal is on the $3^{\text {th }}$ and $5^{\text {th }}$ levels, or if the harmonic filter is activated, it can be eliminated in all orders, or it can be used as a mixture of passive. Filter and filter circuits using cheap passive filters, it is essential to know the parameters of the power system to be connected to avoid resonance. When the system frequency is equal to the harmonic frequency. The amplitude of the voltage and current of the harmonic. Damage to electrical equipment can occur. Inverter circuits use cheap inverters; there is no problem with resonance. A simple installation can add power coordinates by adding parallelism without needing to know the parameters of the system to be added [7]. Analysis of the meaning and general framework of the construction system of offshore wind farms they will focus on the assessment of marine wind resources and the location of individual high-power wind turbine farms in the sea. Installation of the offshore wind farm, disembarking and transmission of sea wind, anti-typhoon and other natural disasters, as well as large scale application of wind power on the sea, to illustrate construction system of the offshore wind farm, Finally a scientific basis and guidance are provided for large scale offshore wind farm building [2]. Single-phase PV system that provides grid voltage support and distortion compensation at a common point due to the repeat controller. The highest energy point tracking algorithm controls the energy received from the solar panel according to the method of increasing the conductivity value that is specially modified to control the phase of the PV inverter voltage. Simulation results and experiments validate the proposed solution according to the objectives [6]. Presentation of single-phase grid-connected inverters for axial permanent magnet generators. Power is transferred using an IGBT inverter that uses a microprocessor as a single-phase power supply. Using 
an inexpensive single-phase grid-connected PV system, including active power filtering function. The system can transfer excess energy to the grid to compensate for the reactive power and harmonics for nonlinear load dispensing, resulting in an almost unified power factor and nearly sine grid current. The system controlled by low price dSPIC30F40. The process of reference to the current creation is thoroughly explained and demonstrated by the waveform of the experiment. There are comparisons of simulation results and experiments to verify the accuracy of the proposed techniques according to the conditions. Single phase power supply via a five-phase permanent magnet generator transformer along the axis to provide DC voltage through a five-series diode bridge rectifier diode. Explain the operation of the converter circuit. The performance of the permanent magnet generator along the proposed axis under various speeds and loads shows satisfactory system performance [8-11]. New high-power tracking technique by integrating ripple relationship control (RCC) with a fuzzy logic controller for photovoltaic systems connected to a single-phase grid. Ripple relationship control is suitable for implementing MPPT in single-phase PV systems and has the advantage of less complexity, low operating costs and high convergence rates. The MPPT technique presented from the RCC that is integrated with the FLC works satisfactorily under different changes. Insolation conditions The effectiveness of the proposed technique has been verified by simulating numerical studies [12].

In this paper, a single stage converter with active and reactive power filter functionality (ARPFF) for control, power filtering single-phase grid-connected photovoltaic system. The proposed system offers multi-functionality, namely the excessive power transfer from the nonlinear load on the grid, simultaneously acting as an active power filter to compensate for reactive power and to mitigate harmonics of the grid current resulting in nearly unity grid power factor, the capability of reactive power control and maximum power point tracking of the photovoltaic modules.

\section{Description of the Proposed Scheme}

Fig. 1 illustrates the schematic of the proposed system consisting of PV panel, a single stage converter, a smoothing inductor, a nonlinear load, a single-phase grid with autotransformer, isolated voltage and current sensors and controls Discrete-Time Integrator block. The dashed line covers the algorithm processed by a DSP-TMS320F28335 (C2000) microcontroller. The power filtering first validates the load-induced harmonic currents in the system, and in the event of the presence of harmonic currents, the filtering scheme subsequently generates the harmonic currents with frequency and size similar to that of the validation but with the opposite direction before supply into the system. The load-induced harmonic currents are thus obliterated by the harmonic currents from the active and reactive power filtering, transforming the currents in the system into non-harmonic currents. Reference currents for energy transfer and harmonic elimination described in the next section.

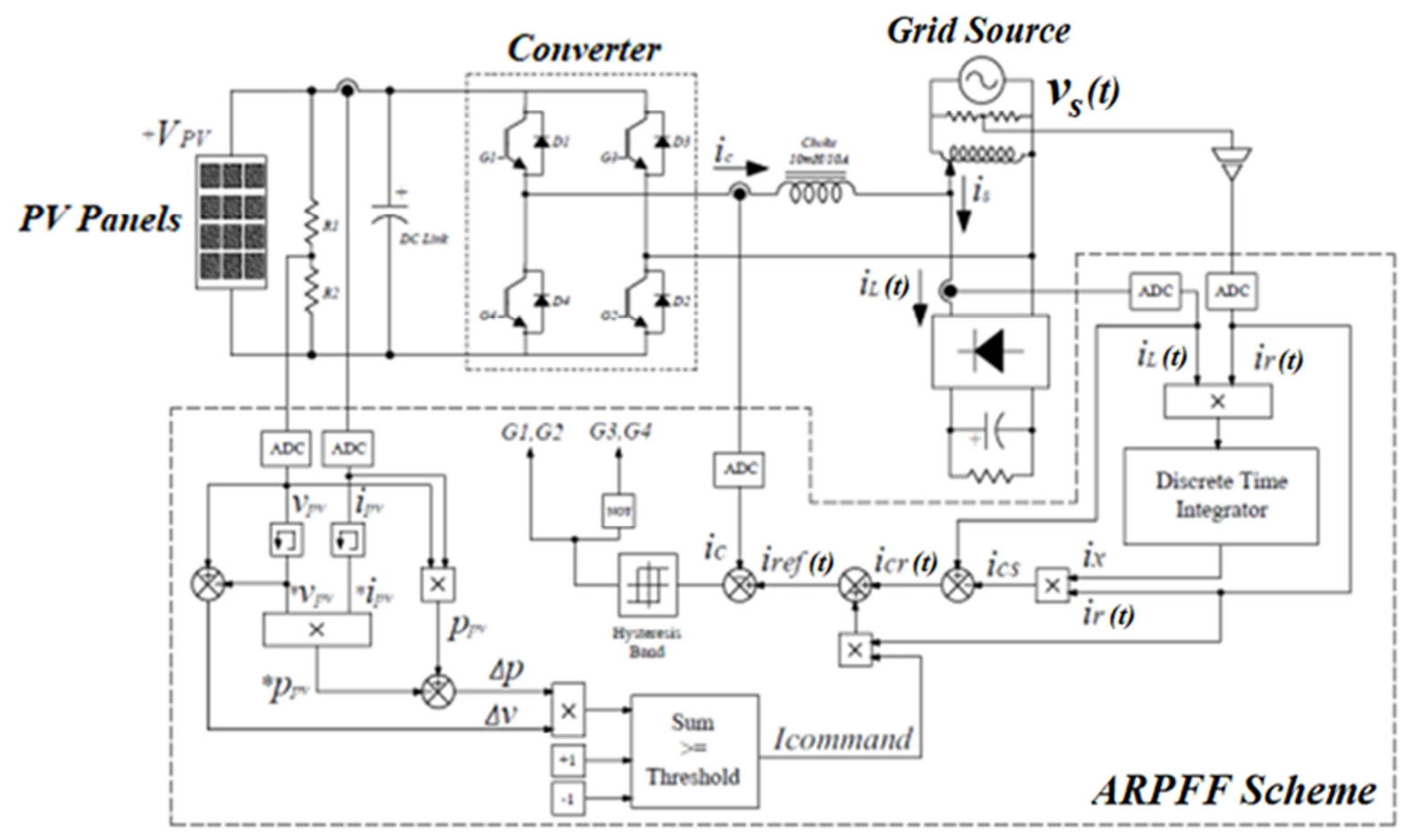

Figure 1. Schematic of the proposed system.

\subsection{Reference Current Calculation}

From Figure 2, the calculation process is different from [2-3]. This process takes into account the energy paid to the load and the transfer to the grid. 


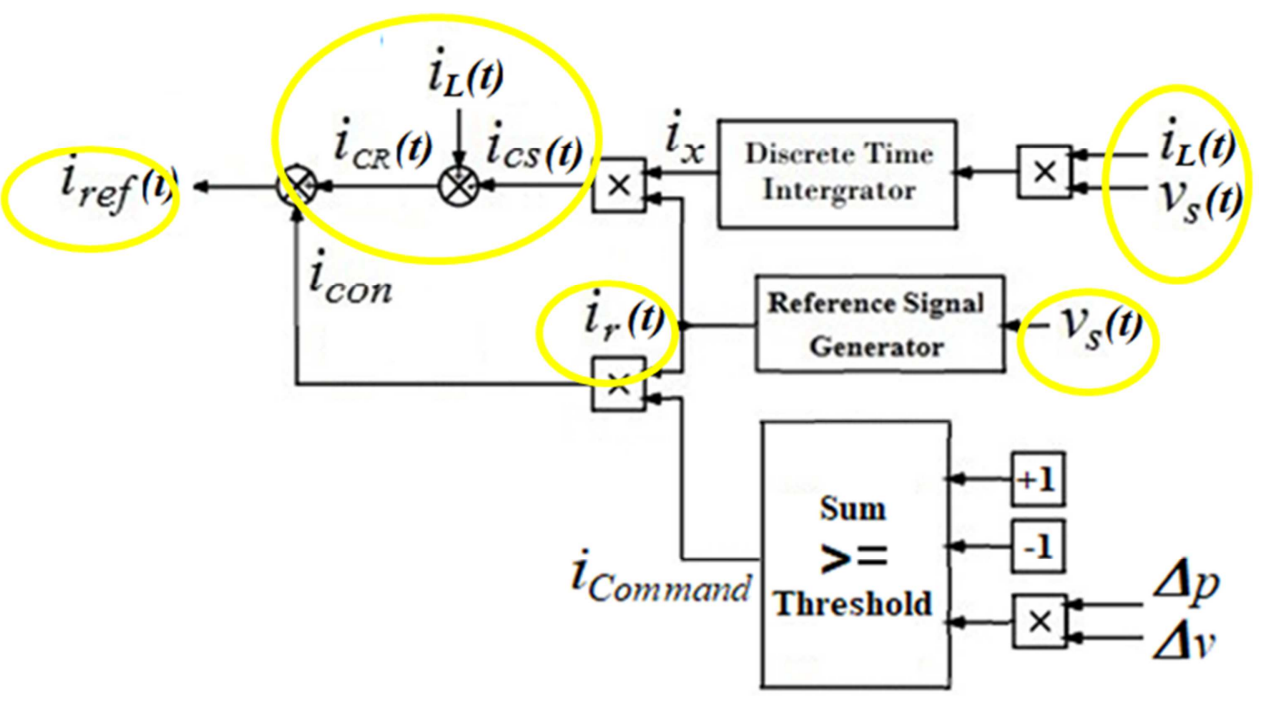

Figure 2. Block diagram of the process of calculating the reference current.

According to the current and voltage definitions shown in Figure 2, the line voltage $v_{S}(t)$ and non-linear load current $i_{L}(t)$ expressed as

$$
v_{s}(t)=V_{m} \sin (\omega t)
$$

Non-linear load current can be written in a Fourier series form as

$$
i_{L}(t)=\sum_{n=1}^{\infty} I_{n} \sin \left(n \omega t+\theta_{n}\right)
$$

Where $\mathrm{n}$ is an order of harmonics. It can be rewritten in terms of the fundamental and harmonic components as

$$
i_{L}(t)=I_{1} \sin \left(\omega t+\theta_{1}\right)+\sum_{n=2}^{\infty} I_{n} \sin \left(n \omega t+\theta_{n}\right)
$$

A per unit reference sinusoidal signal for a case of unity power factor is given as

$$
i_{r}(t)=\sin (\omega t)
$$

Respectively. Then, the load instantaneous real power $p_{L}(t)$ can be calculated as follow

$$
p_{L}(t)=2 \sin \omega t \sum_{n=1}^{\infty} I_{n} \sin \left(n \omega t+\theta_{n}\right)
$$

From equations (5) solves the equation for the average power as

$$
\begin{gathered}
p_{\text {ave }}=\frac{1}{T} \int_{0}^{T} p_{L}(t) d t \\
=\frac{1}{\omega T} \int_{0}^{\omega T}\left(2 I_{1} \sin ^{2} \omega t \cos \theta_{1}\right) d \omega t \\
+\frac{1}{\omega T} \int_{0}^{\omega T}\left(2 \sin \omega t \cos \omega t \sin \theta_{1}\right) d \omega t
\end{gathered}
$$

$$
\begin{gathered}
+\sum_{0}^{\infty} \frac{1}{\omega T} \int_{0}^{\omega T}\left(2 \sin \omega t I_{n} \sin \left(n \omega t+\theta_{n}\right) d \omega t\right. \\
=I_{1} \cos \theta_{1}
\end{gathered}
$$

From equations (6), The average power is equal $=I_{1} \cos \theta_{1}$; This is the maximum current of the grid. The amplitude of the real part of the fundamental of the load current $\left(i_{x}\right)$ can be represented as

$$
\begin{aligned}
& i_{x}=\frac{1}{T} \int_{0}^{T} i_{L}(t) i_{r}(t) d t \\
= & \frac{1}{2} I_{1} \cos \theta_{1}
\end{aligned}
$$

This equation will be computed in the block of Discrete-time Integrator as shown in Figure 1.

Therefore, the real part of the fundamental load current $\left(i_{L}(t)\right)$ as the fundamental frequency, which is the product of $i_{x}$ and $i_{r}(t)$, can be written as

$$
i_{c s}=\left(i_{x}\right)\left(i_{r}(t)=\frac{1}{2} I_{1} \cos \theta_{1} \sin (\omega t)\right.
$$

From equations (3) and (6), it is possible to calculate the reference current as

$$
i_{c r}(t)=i_{L}(t)-i_{c s}(t)
$$

Substituting (2) and (8) in (9) yields

$$
i_{c r}(t)=\sum_{n=1}^{\infty} I_{n} \sin \left(n \omega t+\theta_{n}\right)-\frac{1}{2} I_{1} \cos \theta_{1} \sin (\omega t)
$$

Then, the above equations can be incorporated into the equation $i_{r e f}(t)$ as. 


$$
\begin{aligned}
& i_{\text {ref }}(t)=\sum_{n=1}^{\infty} I_{n} \sin \left(n \omega t+\theta_{n}\right)-\frac{1}{2} I_{1} \cos \theta_{1} \sin (\omega t)+i_{\text {command }} \sin (\omega t) \\
= & \frac{1}{2} I_{1} \cos \theta_{1} \sin (\omega t)+I_{1} \sin \theta_{1} \cos \omega t+\sum_{n=2}^{\infty} I_{n} \sin \left(n \omega t+\theta_{n}\right)+i_{\text {command }} \sin (\omega t) \\
= & {\left[\frac{1}{2} I_{1} \cos \theta_{1}+i_{\text {command }} \sin \omega t\right]+\left[I_{1} \sin \theta_{1} \cos \omega t\right]+\left[\sum_{n=2}^{\infty} I_{n} \sin \left(n \omega t+\theta_{n}\right)\right] }
\end{aligned}
$$

Where $i_{\text {Command }}$ is dc quantity representing the amplitude of a current command responsible for the supplied converter power, and equations (11) it can be seen that in the first semester of the current real power converters are supplied to the load and the grid. During the second term, it is the part of the reactive current that supplies the electrical power that compensates for the load, and in the third term, it is the harmonic current that compensates for the non-linear load.

\subsection{Mathematical Modelling of the PV System}

PV cell is the most basic generation part of a PV system. Single-diode mathematic model is applicable to simulate silicon photovoltaic cells, which consists of a photocurrent source $I_{p h}$, a nonlinear diode $D$, internal resistances $R_{s}$ and $R_{s h}$ as shown in figure 3 . The mathematical relationship for the voltage and current in the single-diode equivalent circuit can be described as

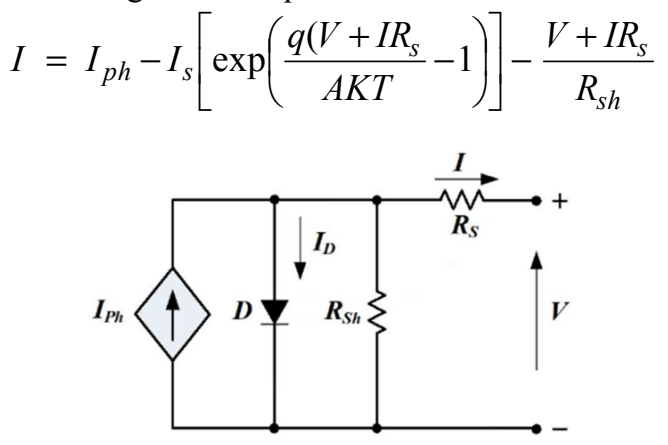

Figure 3. Single-diode mathematical model of a PV cell.

Where $I_{p h}$ is photocurrent; $I_{s}$ is diode saturation current; $q$ is coulomb constant $\left(1.602 \times 10^{-19} \mathrm{C}\right) ; k$ is temperature $(K) ; A$ is a P-N junction ideality factor; $R_{s}$ and $R_{S h}$ are original series resistance [4-5]. The photocurrent is the function of solar radiation and cell temperature described as

$$
I=\left(\frac{S}{S_{r e f}}\right)\left[I_{p h, r e f}+C_{T}\left(T-T_{r e f}\right)\right]
$$

From equation (13), $S$ is the real solar radiation $\left(\mathrm{W} / \mathrm{m}^{2}\right) ; S_{r e f}$; $T_{r e f}, I_{p h r}$ ref is the solar radiation, absolute cell temperature, photocurrent in standard test conditions respectively; $C_{T}$ is the temperature coefficient $(A / K)$.

Also, diode saturation current varies with the cell temperature are expressed as

$$
I_{s}=I_{s, r e f}\left(\frac{T}{T_{r e f}}\right)^{3} \exp \left[\frac{q E_{g}}{A K}\left(\frac{1}{T_{r e f}}-\frac{1}{T}\right)\right]
$$

Where $I_{s, \text { ref }}$ is the diode saturation current in standard test conditions; $E g$ is the band-gap energy of the cell semiconductor, given by the manufacturer according to SHAORISOLAR Photovoltaic Module CRM300S156P-72 Standard

The obtained equations allow representing the I-V characteristic curve of one photovoltaic module under generic temperature and radiation conditions when the characteristic parameters under standard conditions are known as given Table 1 [7-8].

\section{Table 1. Standard Test Condition Data.}

\begin{tabular}{ll}
\hline Electrical characteristics & \\
\hline Cell of Type & Polycrystalline silicon \\
Open circuit Voltage $\left(\mathrm{V}_{\mathrm{oc}}\right)$ & $44.70 \mathrm{~V}$ \\
Short circuit current $\left(\mathrm{I}_{\mathrm{sc}}\right)$ & $8.23 \mathrm{~A}$ \\
Maximum Power Voltage $\left(\mathrm{V}_{\mathrm{pm}}\right)$ & $35.60 \mathrm{~V}$ \\
Maximum Power Current $\left(\mathrm{I}_{\mathrm{pm}}\right)$ & $7.72 \mathrm{~A}$ \\
Maximum Power $\left(\mathrm{P}_{\max }\right)$ & $275 \mathrm{~W}$ \\
Series Fuse Rating & $10 \mathrm{~A}$ \\
Type of output terminal & $\mathrm{Junction}$ Box \\
The temperature coefficient of $\mathrm{I}_{\mathrm{sc}}$ & $\pm 0.0538 \% /{ }^{\circ} \mathrm{C}$ \\
Temperature coefficient of $\mathrm{V}_{\mathrm{oc}}$ & $\pm 0.03321 \% /{ }^{\circ} \mathrm{C}$ \\
The temperature coefficient of Power & $\pm 0.04767 \% /{ }^{\circ} \mathrm{C}$ \\
Temperature range & $-40{ }^{\circ} \mathrm{C}-85^{\circ} \mathrm{C}$ \\
No of cells and connections & $12 \mathrm{x} 6$ in series \\
\hline
\end{tabular}

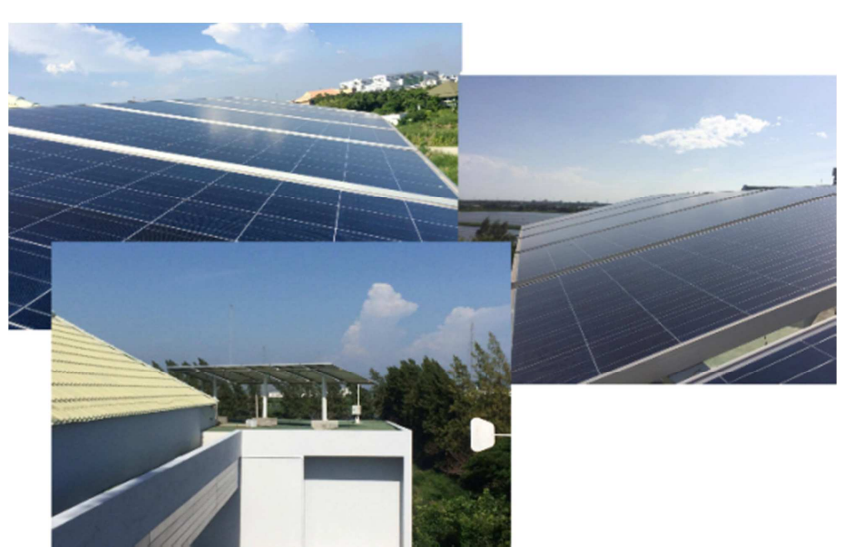

Figure 4. Photovoltaic Module CRM300S156P-72 Standard.

From Figure 4, the installation of a photovoltaic system to test the features of the solar panel and the relationship of the proposed I-V and P-V systems, The array voltage and current are measured, with various temperature and irradiance during June from 10/06/2017 to 20/06/2017 at Samutprakan Thailand. Irradiance is measured using a solar meter, during these days, the irradiance variations from $217.86 \mathrm{w} / \mathrm{m}^{2}$ to $975.75 \mathrm{w} / \mathrm{m}^{2}$, Temperature from $31.5^{\circ} \mathrm{C}$ to $36^{\circ} \mathrm{C}$ and reading during 08.00 A.M to 5.00 P.M. 


\subsection{DSP Program Design}

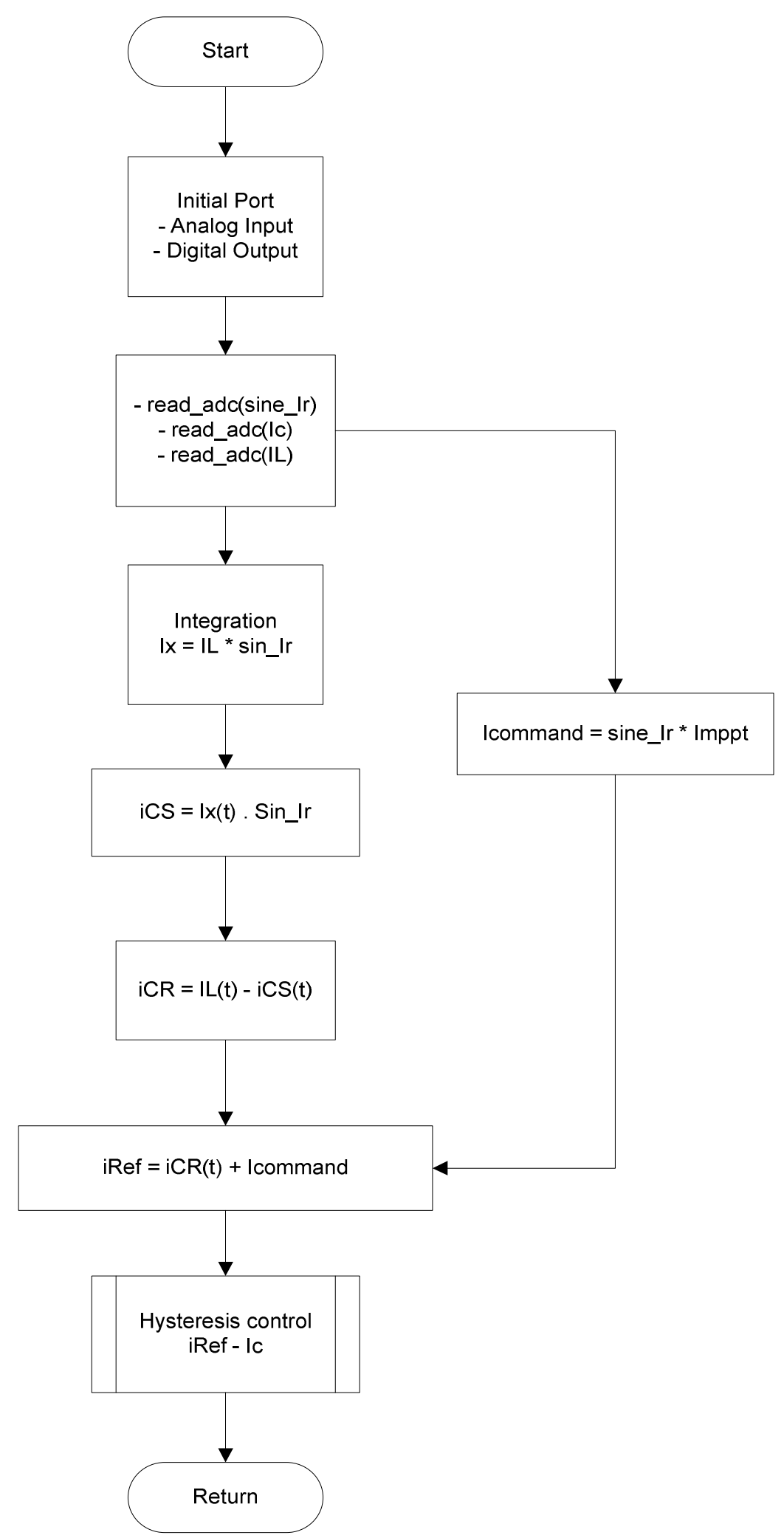

Figure 5. Flowchart for programming DSP-TMS320F28335 (C2000) microcontroller.

The PV system connects single-phase grids to explain the functionality. Flow chart for DSP-TMS320F28335(C2000) microcontroller programming is shown in Figure 5, starting with the port setting, timer, ADC and DAC. A lookup table contains 500 sinusoidal values. Then the synchronisation with the grid system using zero crossings is performed via ADC. The search table is used for reading sine values with sufficient resolution for synthesising sineides equivalent to 
100 microseconds. This is the sampling time that Timer 2 controls. Then subroutine of compensation for calculating the reference current and bang-bang hysteresis current control for generating gate signal of the main power circuit is performed respectively. Whenever the zero crossing signal, the sine begins to read at that point. These steps are the block control diagram as shown in Figure 1.

\subsection{The MPPT Algorithm}

To extract the maximum power from the PV array and, therefore, maximising its efficiency, perturb-and observes
(P\&O) maximum power point tracking (MPPT) technique [4] is employed as shown in Figure 6. This MPPT algorithm operates, continuously, incrementing or decrementing both the output voltage and current of the PV array. It performs a comparison between the PV power $\left(P_{P V}\right)$ and $\mathrm{PV}$ voltage $\left(V_{P V}\right)$, obtained in the current cycle, with the respective $\Delta_{p}$ and $\Delta_{v}$ quantities obtained in a previous cycle. If the PV array power increase and its voltage also increase, the control increases the voltage reference. On the other hand, if the voltage decreases the voltage reference must decrease. An inverse logic is adopted when the PV array power decreases.

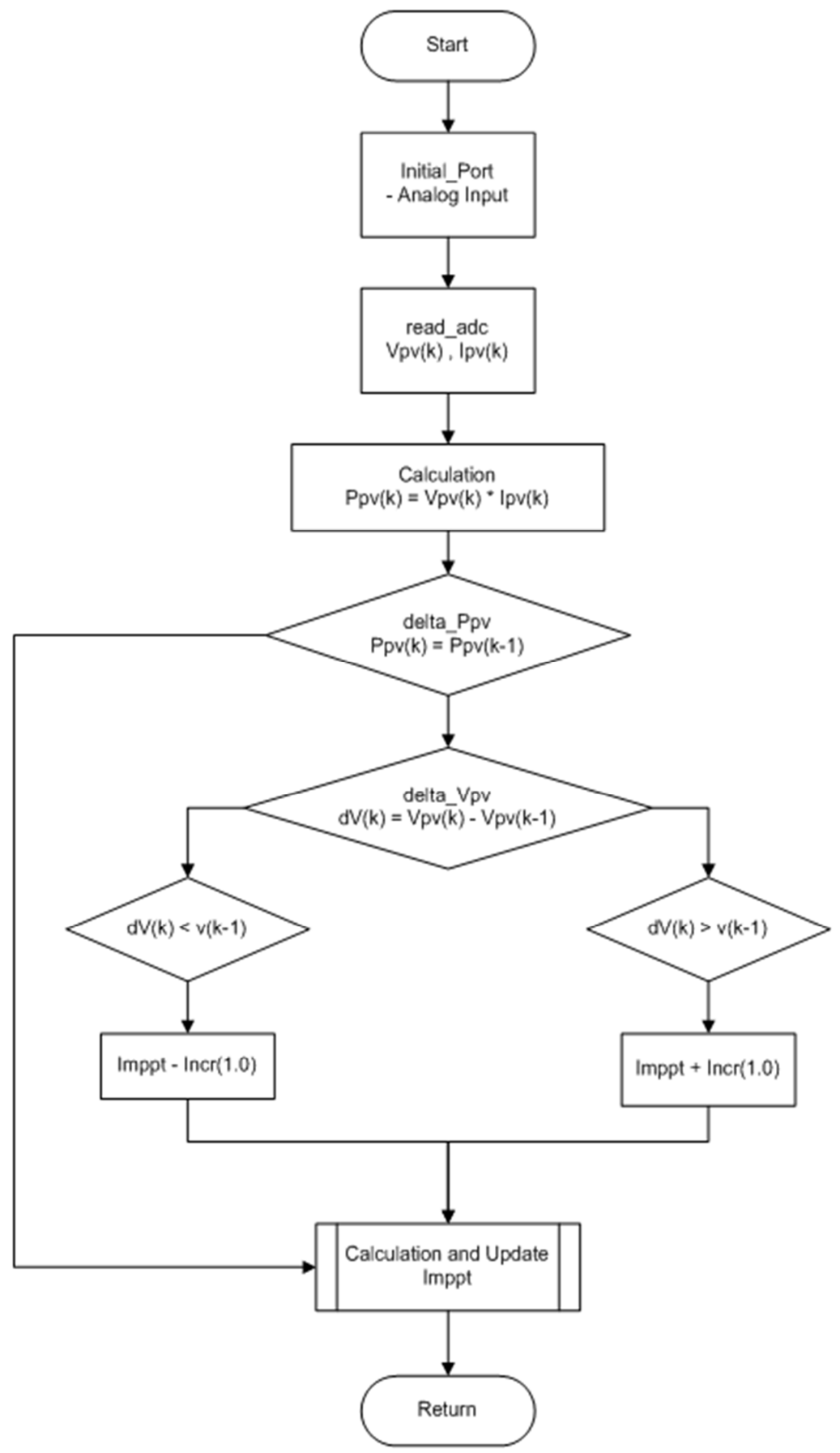

Figure 6. Flow Chart Diagram Perturb and observe (P\&O). 


\section{Results and Discussion}

This research, the proposed system with active and reactive power filtering mechanism before the development of a prototype. When testing the operation of photovoltaic systems connected converters with integrated power load is non-linear tracking maximum power. The research conducted by the command current $\left(i_{\text {Command }}\right)$ Peak values of up to $10 \mathrm{~A}$, and set a minimum current value of 0 A system of tracking the maximum power detector voltage and electric current side. Output the voltage and current of the photovoltaic system pay into a series of energy (DC Link) to calculate the ratio of the power to change the voltage to calculate the current value used to flow control current command. The command current returns the following test as Figure 7. Consider figure 7 (a) and (b), a system to track the maximum power of the light intensity in the test is equal to $684.57 \mathrm{~W} / \mathrm{m}^{2}$ to start current command is equal to $0 \mathrm{~A}$, and the current increases in the order of condition sensing. Voltage and current to calculate the ratio of the power to change the voltage to adjust the appropriate command for tracking the maximum power.

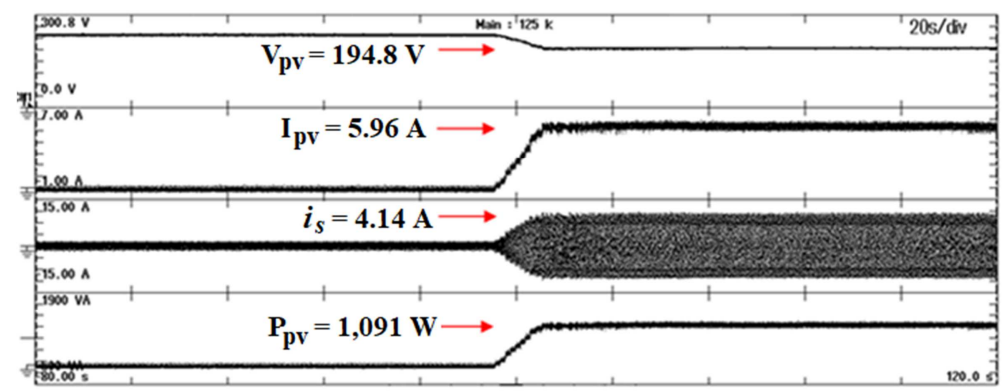

(a) $P_{p v}$ and $I_{p v}$ when light intensity is increased
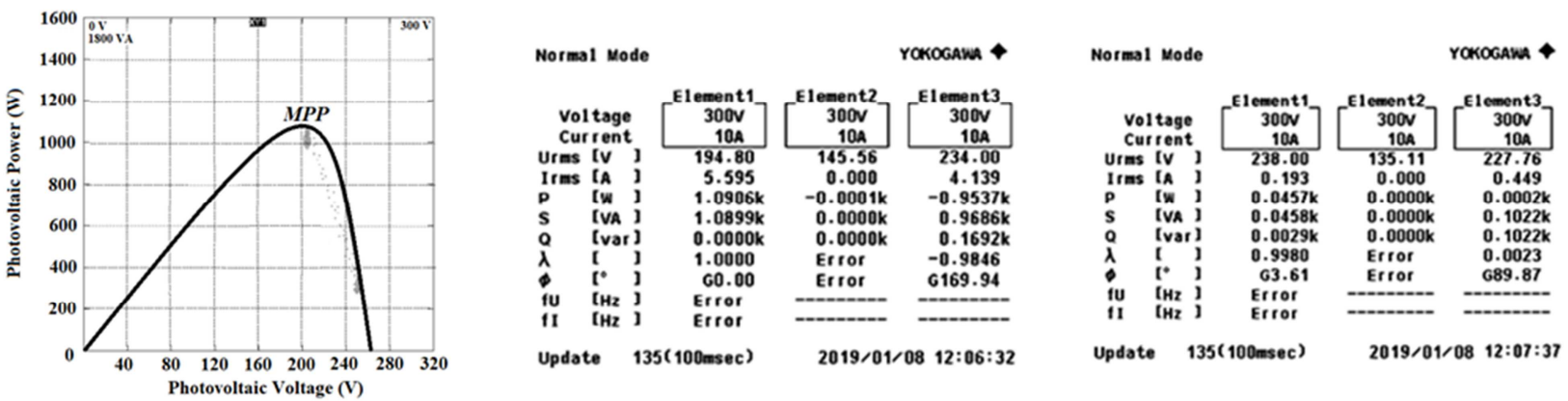

Figure 7. The measuring $(P),(S),(Q)$ and $(\lambda)$ of a prototype when light intensity increased.

It also found that the voltage photovoltaic is equal to 194.8 $\mathrm{V}_{\text {rms }}$ flow of photovoltaic panels on the order increase is equal to $5.959 \mathrm{~A}_{\text {rms }}$ grid network began tracking system can act as a filter for sensitivity to compensate. Virtual power and reduce harmonic currents of the grid network resulted in a power factor near to one. From Figure 7 (c) and (d) when measuring the real power $(\mathrm{P})$, the apparent power $(\mathrm{S})$ and the instantaneous power $(\mathrm{Q})$ and the power factor $(\lambda)$ with power analyse (Yogokawa WT500). Starting from the command current $\left(i_{\text {Command }}\right)$ is equal to $0 \mathrm{~A}$ and when the maximum order command current is equal to $8 \mathrm{~A}$, the instantaneous power (Q) supply system enters the grid and also causes the power factor to be equal to 0.9980 , that is, having a value approaching one according to the specified condition multifunction.

The test conditions tracked and the phenomenon of light fell upon the nature of the research was to reduce the volume command current $\left(i_{\text {Command }}\right)$ Peak less to maintain power by changing the voltage and current at the output. The test results were as follows:

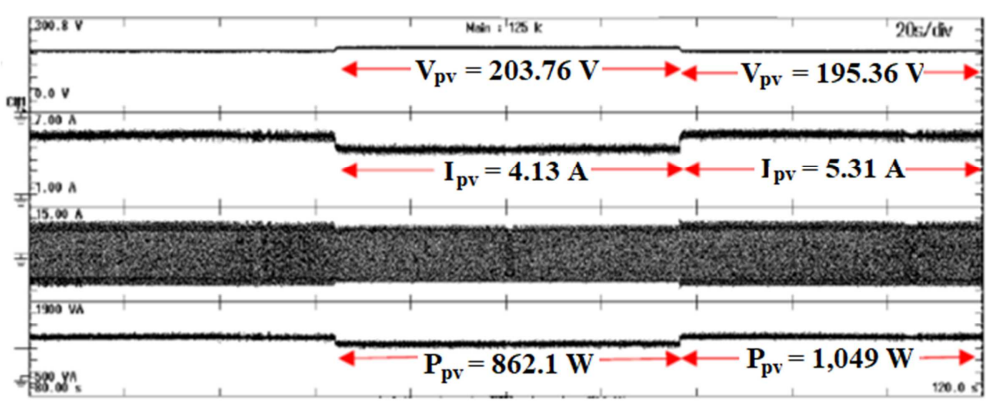

(a) The system works when the light intensity changes abruptly. 

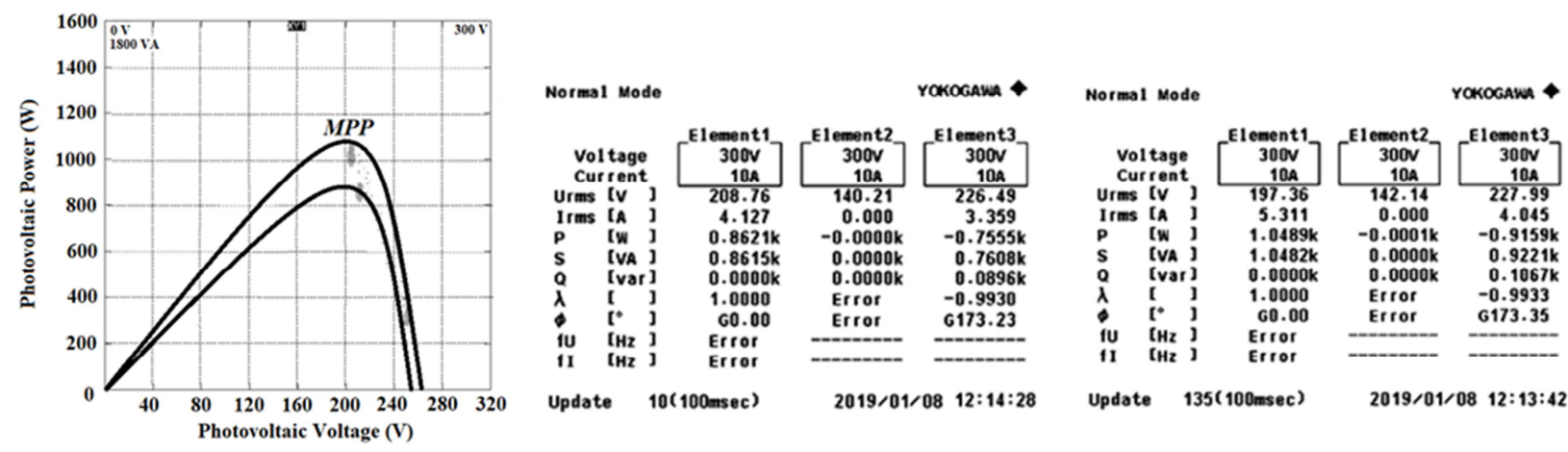

Figure 8. The measuring $(P),(S),(Q)$ and $(\lambda)$ of a prototype when light intensity changes abruptly.

Consider Figure 8 (a) and (b), and the test conditions monitored and reduced natural light phenomenon. The system tracks the maximum power from the solar panels to reduce the amount of current command less to maintain power by changing the voltage and current at the output. The results showed that the performance of the system maximum power output of photovoltaics. The phenomenon of the incident light onto the natural photovoltaic decline of a sudden the light intensity $658.40 \mathrm{~W} / \mathrm{m}^{2}$ and $541.14 \mathrm{~W} / \mathrm{m}^{2}$ making the power of photovoltaic, resulting in a reduced statement command current measures reduced in proportion to the sum of the power and voltage of the photovoltaic. The system built, it serves power transfer excess load is not linear to the electricity network and also acts as a filter for sensitivity to compensate for virtual and reduce harmonics of a stream.

Similarly, when using a power analyser (Yogokawa WT500) to measure amplitude $\mathrm{P}, \mathrm{S}, \mathrm{Q}$, and $\lambda$ the figure 8 (c) and (d) It found that even though the light intensity changes the power supply into the grid, the power factor is equal to one. When the operation of photovoltaic systems connected converters with integrated power under no-load linear per share, the researchers tested the photovoltaics installed on the roof of the building engineering. Dhonburi Rajabhat University Samutprakan, with tracking the maximum power light on natural phenomena, the real-time is a relationship of voltage network $\left(v_{s}\right)$ electricity network $\left(i_{s}\right)$ a voltage converter $\left(v_{c}\right)$, and electricity converters $\left(i_{c}\right)$ Figure 9.

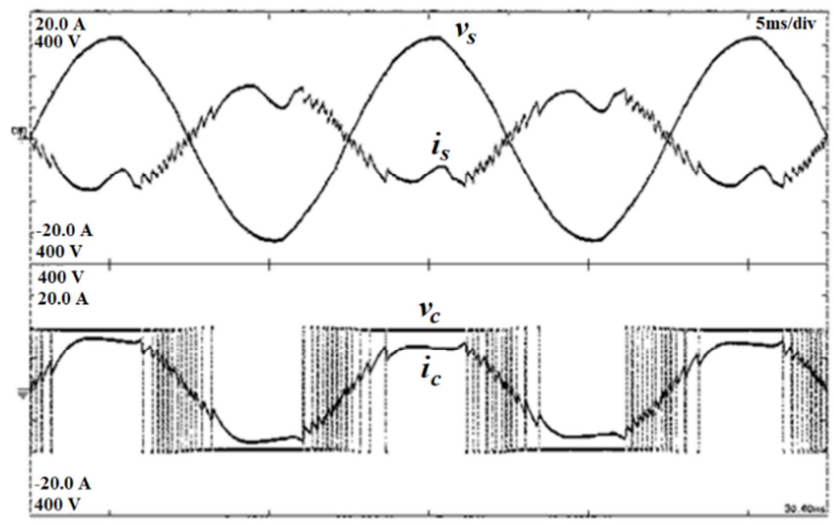

Figure 9. Voltage and current when light intensity increased.

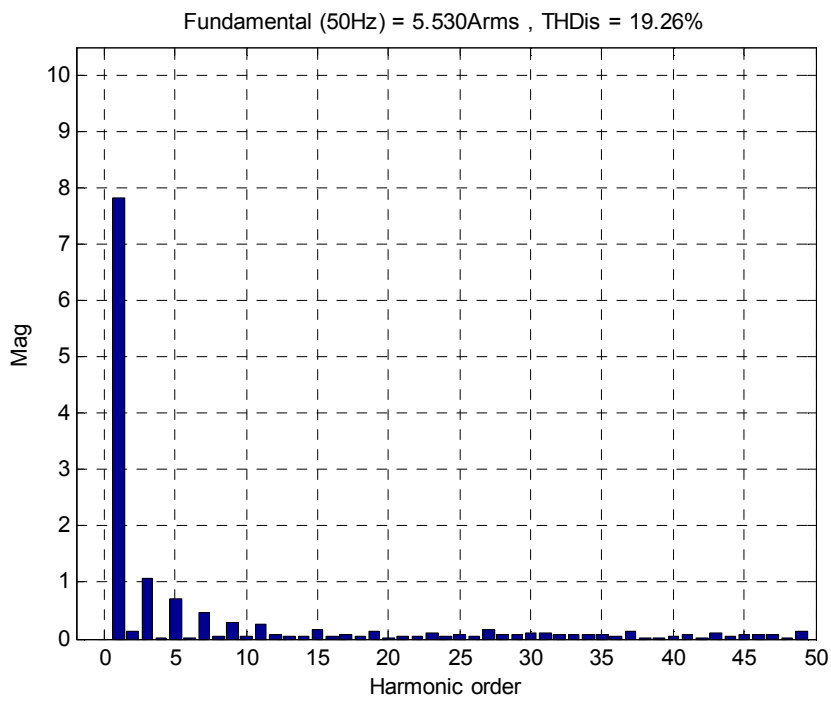

Figure 10. Total harmonic distortion.

Figure 9, shows that when the light intensity increases modulation. An amplitude of the signal based on the modulation using the multiplying voltage and electric current to the electric power generated by real-time to find the difference of power that occurred at that time compared to the electric power during the first thus increasing or decreasing the size of the current command to increase or decrease power. The converter makes the current converters, an over-modulation, which is a due amplitude of the reference current rather than flow converters, as mentioned above. Result in the distortion of current harmonics in Figure 10, and considering the spectral harmonics of a stream is going to find that the foundation first current increased disproportionately by the changes the intensity of the light and the harmonic distortion total (THD) is decreased.

\section{Conclusion}

The research topic Multi-functionality control, Power filtering single-phase grid-connected photovoltaic system. The researcher tested the system created under the state of tracking the peak power at the intensity of light changes naturally and suddenly. Moreover, there is a non-linear load with the grid network. The power supply is similar to the power grid as the schematic proposed system mentioned above. It based on testing by defining the command current 
from the maximum power tracing, comparing it to the reference sinusoidal signal one per unit that has a phase corresponding to the grid voltage. Moreover, compared with the harmonic current caused by the amplitude of the load current subtracted from the actual current of the load at the fundamental frequency. The actual current of this load derived from the product of the maximum current amplitude of the grid and the current amplitude of the reference sine. Also, using this reference current to compare the current size of the converter to determine the extent of the hysteresis current and control the IGBT switch. To control active and reactive power filter functionality, Which proved that the above equations are correct and meet the conditions set forth multi-functionality. The results of the test showed that the prototype could control the virtual power supply and harmonics of the electric network current, resulting in a power factor closer to one. Also, it is a confirmation of the validity of the algorithms and techniques.

\section{Acknowledgements}

This work supported by Dhonburi Rajabhat University, Thailand and Faculty of Engineering, King Mongkut's Institute of Technology Ladkrabang, Thailand. The authors would like to thank Prof. Vijit Kinnares give advice and $\mathrm{Mr}$ Sakdawut Boontua, for the experimental setup.

\section{References}

[1] Changchien, S., T. J.Liang, J. F. Chen, and L. S. Yang. 2010. "Novel High Step-Up DC-DC Converter for Fuel Cell Energy Conversion System." IEEE Transactions on Industrial Electronics 57 (6), 2007-2017.

[2] Liu, P. Z., and M. Fang. 2010. "Research on Construction System of Large Scale Non-Grid-Connected Wind Power Offshore Wind Farms.” In 2010 World Non-Grid-Connected Wind Power and Energy Conference (WNWEC), Nanjing, 5-7 November 2010: 1-5. IEEE. doi: 10.1109/WNWEC.2010.5673119.

[3] Roman, E., R. Alonso, P. Ibanez, S. Elorduizapatarietxe, and D. Goitia. 2006. "Intelligent PV Module for Grid-Connected PV Systems" IEEE Transactions on Industrial Electronics 53 (4): 1066-1073. doi:10.1109/TIE.2006.878327.

[4] Seul-Ki Kim., Jin-Hong Jeon., Chang-Hee Cho., Eung-Sang
Kim., Jong - Bo Ahn "Modeling and simulation of a grid-connected PV generation system for electromagnetic transient analysis" Solar Energy 83: 664-678, 2009.

[5] Akagi, H., and K. Isozaki. 2012."A Hybrid Active Filter for a Three-Phase 12-Pulse Diode Rectifier Used as the Front End of a Medium-Voltage Motor Drive" IEEE Transactions on $\begin{array}{llll}\text { Power } & \text { Electronics } & 27 & \text { (1): }\end{array}$ doi:10.1109/TPEL.2011.2157977.

[6] Rosa A. Mastromauro, Marco Liserre, Tamas Kerekes, and Antonio Dell' Aquila, "A Single-Phase Voltage-Controlled Grid-Connected Photovoltaic System With Power Quality Conditioner Functionality," IEEE Trans. Industrial Electronics., Vol. 56(11): 4436-4444, 2009.

[7] Jou, H.-L., J.-C. Wu, and H.-Y. Chu. 1994. "New Single-Phase Active Power Filter." IEE Proceedings - Electric Power Applications 141 (3), 129-134. doi: 10.1049/ip-epa:19949938.

[8] Chaithanakulwat, A., V. Kinnares, and N. Thungsuk. 2012. "Modeling and Simulation of a 3-Phase Grid-Connected Photovoltaic Inverter with Active Power Filter Functionality for Harmonic Mitigation." The International Conference on Electrical Engineering (ICEE 2012), Kanazawa, 8-12 July 2012: 186-190.

[9] Chaithanakulwat, A., V. Kinnares, and N. Thungsuk. 2012. "Single-Phase Grid-Connected Photovoltaic System with Active Power Filter Functionality.” In 2012 15th International Conference on Electrical Machines and System (ICEMS), Sapporo, 21-24 October 2012: 175-177. IEEE.

[10] Wannakarn, P., and V. Kinnares. 2002. "Digital Signal Controller Based Grid-Connected Inverter for Axial Flux Permanent Magnet Generator." In 2011 IEEE Ninth International Conference on Power Electronics and Drive Systems (PEDS), Singapore, 5-8 December 2011: 1527-1530. IEEE.

[11] Arckarakit Chaithanakulwat, Vijit Kinnares 2017. "Implementation of a Low-Cost Single-Phase Grid-Connected Photovoltaic System with Active Power Filtering Mechanism" International Review of Electrical Engineering (I.R.E.E.) Vil. 12, N.2, 175-182. Doi:10.15866/ire.v12i2.11383.

[12] Ch. L. S. Srinivas, Sreeraj E. S. "A Maximum Power Point Tracking Technique Based on Ripple Correlation Control for Single Phase Photovoltaic System with Fuzzy Logic Controller" 5th International Conference on Advances in Energy Research, ICAER 2015, 15-17 December 2015, Mumbai, India. 